\title{
Literature and Academic Freedom
}

\author{
Gassim H. Dohal
}

\begin{abstract}
Whenever there is freedom on one side, there is also an obligation [a work to do, a space to fill, etc.] on the other, or limitations that academics may not be aware of. However, limitations such as ideology, educational system, and conventions are always there whether recognized or not. Such limitations affect our opinions and discussions which are important to teachers of literature who usually address controversial, social, cultural, and political issues.

On the other hand, as teachers of literature, we have to give our students a chance to discover, explore, and expand knowledge for themselves.

In the light of what is mentioned above, my paper will address the concept of academic freedom in educational literary environment, referring to some practices that take place in my university.
\end{abstract}

Index Terms-Academic freedom, forces, limitations, literature, teach.

\section{INTRODUCTION}

The most important aspect of freedom of speech is freedom to learn. All education is a continuous dialogue — questions and answers that pursue every problem on the horizon. That is the essence of academic freedom. William Orville Douglas [1].

Discussing the academic freedom of speech and expression poses many questions when literature becomes our topic. What does this academic freedom mean in general and to both those who study and those who teach literature in particular? When and where does it exist and how? What are the forces that affect and limit this freedom? Indeed, there are these and many other related questions.

Merriam-Webster dictionary dates the phrase "academic freedom" to as early as 1901 with the meaning: "freedom to teach or to learn without interference (as by government officials)." This definition was introduced at a very important period when universities were founded as state apparatus that had social and political missions. The definition is short and comprehensive at the same time. "To teach or to learn" indicates that this freedom takes place in educational academic institutions, which are now universities and colleges. "To teach" entitles faculty to have this freedom while "to learn" bestows this freedom on students, particularly the ones who study literary texts with controversial issues. In the article "Defining Academic Freedom," Cary Nelson argues:

Academic freedom gives both students and faculty the right to express their views - in speech, writing, and through electronic communication, both on and off campus - without

Manuscript received October 6, 2015; revised December 18, 2015.

Gassim H. Dohal is with Al-Imam Muhammad ibn Saud Islamic University, Saudi Arabia (e-mail: dr_waitme@hotmail.com). fear of sanction, unless the manner of expression substantially impairs the right of others or, in the case of faculty members, those views demonstrate that they are professionally ignorant, incompetent, or dishonest with regard to their discipline or fields of expertise [2].

With regard to "interference," there are external and internal forces that may affect this freedom. I mean by "internal forces" ideologies, desires, and tendencies that one might have. They may restrict the research to achieving a specific result. Anyone with such internal forces may, in turn, intend to serve an ultimate end. On the other hand, the external forces include government officials, dominant culture, and the board of trustees and officials in the universities. Both types of forces may limit and/or hinder the search for knowledge in literary texts more than any other subject because the main concerns in literature are ideas and opinions. In fact as Cary Nelson states in his article,

Academic freedom does not give students or faculty the right to ignore college or university regulations, though it does give faculty and students the right to criticize regulations they believe are unfair [2].

Those rights should be realized by both sides if and when there is a chance to develop academic freedom; each party should recognize the other's rights. Unfortunately and in many cases, educational institutions force regulations. In certain cases consequences may lead to terminating the job. Usually when it comes to the source of living, one may sacrifice his rights. Accordingly, those institutions put an end to "the common good" [3] for which they are established; it is TRUTH and KNOWLEDGE.

\section{RESEARCH BODY}

The common good of any society depends upon the search for knowledge that leads to the free exposition of truth. Academic freedom in universities is essential to the exposition of truth. Edward L. Pincoffs (1972) argues:

When a professor or a student claims that he is entitled to academic freedom he is generally under-stood to be claiming the right to pursue the truth unhindered (viii) [4].

The growth of any institution depends on the discovery, publication, and teaching of ideas which might be controversial and confusing to some people. So, to explore literary theories, to study different literary texts, and to discuss opinions and ideas require academic freedom. Hence, in a well-known novel like Daniel Defoe's Robinson Crusoe, let the other novel alone, a lot of issues might be addressed like the igo, the center, the self, the political atmosphere prevailing at that time, religion, colonialism, etc. and in a 
closed and/or conservative society, some of these points, if not all, should be avoided or ignored on purpose.

Like any other literary book, in Robinson Crusoe there might be some lapses that could be traced depending on the culture in question, yet we, as professors, can comment and guide our students regarding what might be considered controversial in the novel. Students should be reminded that the novel represents another culture. So students in an Islamic community may find it hard to see Robinson as a hero ignore his father's advice and insist on leaving home without having his father's permission. It is a chance to let students think about Robinson's decision and express their opinions frankly and freely. Teaching this novel, I asked my students in the final, "Imagine you are Robinson, what are the things he did you should not do?" An optional question like this may give some students a chance to address this issue and express their views, but unfortunately no one answered this question because they believe that questions should be objective. The educational system develops in them how to memorize, not how to analyze. This is a burden I try to overcome, yet it is a cultural, societal, and educational issue. Another example is when Robinson sells his companion as a slave, manipulates, and uses African individuals to establish his colony in that isolated island. My students feel they cannot talk about topics they have not experienced. Hence, sometimes it is the environment you are teaching at that does not help you experience academic freedom.

As educational environments, universities exist not only to transmit existing knowledge, but also to interpret, explore, and expand that existing knowledge in order to propose new knowledge. Accordingly, on a free and open campus, no idea or view can be banned or forbidden for unsatisfactory reasons. We read about some texts that are banned for social, religious and/or political reasons. At Al-Imam University, a colleague used to teach Shakespeare's Macbeth for years, and then he was asked to stop teaching this play because of the witches it has. Every society has its limitations, regulations, and principles that may hinder, discourage, and/or add some burden to those who practice and enjoy academic freedom. For example, at Shakespeare's time women are not allowed to appear or take part on the stage, and boys take turns to represent women. Well, if these people have a chance to see what is taken place nowadays, what will they do? On the other hand, Macbeth is a well-known tragedy which dramatizes certain events, beliefs, and tendencies that prevail in Scotland around the eleventh century. Hence, it is a dramatized history that belongs to a different culture, and studying this play will shed light on that history and enable us to get lessons from what took place in the past. Some fanatic people see in the first pages a challenge to their religious culture as if witchcraft has no presence at all nowadays; Macbeth begins with the following conversation:

\footnotetext{
1st Witch: When shall me thee meet again? In thunder, lightening, or in rain?

2nd Witch: When the hurly-burly's done, When the battle's lost, and won.

3rd Witch: That will be ere the set of sun.

$I^{\text {st }}$ Witch: Where the place?

$2^{\text {nd }}$ Witch: Upon the Heath.
}

\section{$3^{\text {rd }}$ Witch: There to meet with Macbeth (I.i.1-8) [5].}

A text like the one above will not lead people to adopt or reject witchcraft. By the way, some people believe in witchcraft to achieve their goals nowadays. However, there are many blurring and confusing issues that might be understood differently by different people, but this difference does not mean that we should block others' views; various viewpoints entitle academic freedom. Anyhow, professors should realize that relationships among people usually depend on power and how some use it; some influential and high-ranking individuals may force their opinions and completely ignore others regardless of who they are and/or how far they care. At universities and colleges, such individuals may discourage freedom, and become a stumbling block in the face of those who practice academic freedom, trying to explore knowledge to its full extent.

Some parts of particular literary texts might be taken out of their contexts and cause some problems in some societies; in a Muslim society, because God is presented and talks in Everyman, this short morality play is not allowed to be taught in my college. A fanatic student found a translated text for the dialogue that takes place between God and Death at the beginning of that morality play,

God: I perceive, here in my majesty,

How that all creatures be to me unkind,

In worldly riches is all their mind;

They fear not my righteousness, the sharp rod.

......

That needs on them I must do justice,

On every man living without fear.

\section{Go thou to Everymen}

And show him, in my name,

A pilgrimage he must on him take,

$$
\text { ..... }
$$

Without delay or any tarrying (pp. 22-71) [6].

That student used the translation as a means to ban teaching this short play at the college when he presented the translation to a religious scholar, requesting a fatwa [religious decision]. Indeed, such a play might be put into its historical and social context. In addition to its literary and historical importance, students should realize that this play belongs to a different culture. Everymen tells the end of Everymen's life when all friends leave except Good Deeds, who says at the end,

\section{Nay, Everymen, I will bide with thee. \\ I will not forsake thee in deed; \\ Thou shalt find me a good friend at need. (pp.} 852-854) [6].

In fact, an institution cannot fulfill its mission if it tends to prescribe ideas and opinions. Prescribing ideas and rules made by the administrators might be introduced and presented to the teachers and students in the form of an internal constitution or in the form of laws imposed by the ruling officials. Usually, institutions tend to present and implement a 
particular ideology in order to support the dominant culture. Writing about the USA, Sidney Hook (1971) points out that:

Academic freedom in the United States today is threatened not so much by fundamentalist churchmen, reactionary businessmen, and political demagogues, as it is by ideological fantasies among students and faculty (118) [7].

And if this is the case in the United States, what could be said about other societies and countries and their dogmas?

Ideology, as David R. Shumway (1994) states, "is expressed everywhere, including in literary works where it may be explicit or implicit" (32) [8] with different degrees depending on rules, obligations, and the limitations people have. Often it is hard to determine whether academic scholars are influenced by the ideology of the literary texts they choose, discuss, research, and explore. Probably a professor chooses a text because it has the professor's beliefs and tendencies. In this case, s/he will defend the text rather than examine and explore that text. Consequently, this professor may impose ideas and opinions on students. Thus, this professor will not add any new knowledge; instead s/he will emphasize the old knowledge. Emphasizing old knowledge in itself does not contradict academic freedom, but who can ascertain that this professor is not biased toward his/her gender, race, and tradition. By the way, at the College of Languages and Translation, Al-Imam University, all professors should abide by the minute syllabi provided by the Unit of Quality where literary texts, themes, and topics are determined in advance in order to achieve what is called "unified questions" for both genders in the College of Languages and Translation for they are taught separately. Apparently, it is a requirement for accreditation, but in reality, it is a way of prescribing what to be taught and how to be taught. In addition, the ultimate goal is defined in advance, i.e. the questions at the end of the semester. All these given elements discourage and curtail freedom.

However, many issues are relative. Thomas L. Pangle (1992) points out that:

"We" relativistic liberals, who constitute the "civilized," cherish our freedoms "on the public side of our lives," while "on the private side of our lives," there are certain rather different claims that are "equally hard to doubt" (58) [9].

Indeed, there are some points that might be raised here:

First, there are many things that interfere in one's life and determine a lot of his/her decisions such as ideology, race, gender, class, etc. A professor may adopt a literary theory or movement as an advocate rather than as a critic. S/he defends such a movement rather than explores its depth, dimensions, and limits and gives students their academic freedom to explore such a theory. Accordingly, students may say or write things that they do not believe in or accept as their free and frank opinions. They write what the professor wants because they want to get a good grade in the course.

Second, the names of the literary courses should be general and comprehensive. This gives a professor a chance to put specific areas or genres to be presented in that course. For example, a course with the name of Postmodernism gives professors but not necessarily students more freedom. As I mentioned earlier, students may be deprived of their academic freedom when the professor becomes an advocate rather than a critic of what $\mathrm{s} / \mathrm{he}$ is presenting.

Third, in many cases, faculties are hired to fit an expected position. This expectation in advance may put some limits on the faculty's freedom as well. The professor has to present the course in a way that attracts students to register for the course. Otherwise, s/he will end up with no students. Hence,

Teachers, especially those whose evaluations are based on class size and student opinion surveys, feel pressure to please their audiences, sometimes at the expense of educational goals (3) [10].

Indeed, in my college, both class size and student surveys are crucial to classify professors and let him teach a course or not. Hiring someone to fit an appropriate place may be good and in favour of academic freedom, particularly when that person has enough knowledge and is interested in exploring and expanding the available knowledge. On the other hand, some students may lose their freedom because of their professors' attitudes towards them. However, discussions in class should go beyond the limits of the assigned texts. A lot of important issues should be raised and students are to give different opinions that enrich the discussion and enhance research. And professors should avoid forcing students to do specific things or believe in them.

Anyhow, whenever there is an obligation [a job to do or a space to fill or things like these], there is a lack of freedom, and vice versa. Whenever a professor or a student feels that $\mathrm{s} /$ he has something to do or a space to fill, this means that there is a burden on that person. Any kind of burden will affect the degree of freedom. A professor might be hired to represent a minority or a focus; this is a burden.

According to Jeffrey Wallen (1998), certain people are viewed as "representatives of specific cultural identities [while] the ideal of diversity is one in which class, gender, and race no longer have the defining impact that they are often said to have" (51) [11]. When a minority faculty is hired in order to achieve diversity in terms of identity, this fact puts strong pressures on him/her to conform to the identity. On the other hand, a diversity of opinion is at the heart of traditional academic freedom because it is through different opinions that we can explore and expand our knowledge. For religious, cultural and methodological reasons, there are many issues professors avoid to thoroughly and explicitly discuss like deconstruction, sexuality, anti-religious and anti-cultural points at different schools and universities though it is hard to find a literary text that does not contain any of these topics.

Another requirement set by the Quality Unit in my college is that when few professors teach the same course for different sections, they are required to "collaborate"; this is their term, regarding the set-in-advance topics to be addressed, discussed, and analyzed and should have same questions for the final exam. This process entitles professors less space and narrows their academic freedom, particularly while teaching literary texts that rely on opinions, views, and differences, not similarities. This requirement could be applicable while teaching, say grammar, phonetics, and research methods if professors agree on the assigned text.

As a whole, Wallen makes it clear that "when it is specified in advance what a student is to hear from these 'other' voices, 
the power of dominant institutions to determine meaning is strengthened" (53) [11]. And whenever a student's or a professor's opinions are to be judged and expected in advance according to its significance for the speaker and the hearer, then academic freedom is severely, if not completely, curtailed. Consequently, we realize why "the American Association of University Professors, which was formed in 1915 in order to promote and defend academic freedom, no longer feels secure in its mission" (Wallen 46) [emphasis added] [11]. What we have now are institutions that constitute, in Louis Althusser's term, "Ideological State Apparatus" [12] used to embed ideologies of the powerful and dominant class. Hence, our academic freedom is curtailed.

Indeed, academic freedom requires a great degree of autonomy. Its autonomy should be defended against the external threats including trustees, administrators, and other zealous colleagues and the internal threats that are based on personal bias as well. On the other hand, freedom of expression requires toleration of opinions and ideas we may not like rather than imposing unjustified rules and limiting the scope of freedom.

Imposing and implementing rules may be invisible to the public, but as academics, we have to admit that there are interests of some factions in the field of literature. Shumway, who is concerned about American Literature, states that "the constitution of American literature as a field served the interests of particular factions within the profession and those of dominant class, race, and gender within American society" (9) [8]; what is applicable to the American society might be found in any society. If there are interests in this field, then who guarantees that the factions that have "interests" will not directly or indirectly affect academic freedom? As a matter of fact, we have to admit that:

We now know that these freedoms [academic freedom and freedom of speech] often shield the interests of those in power, are part of the fabric of oppressive institutions, and only help produce a false sense of "autonomy" or a misguided "quest for truth" (Wallen 38) [11].

Moreover, all faculty and students are entitled to freedom in research as well. As professors, we have to follow instructions given by editors of the journals we intend to publish in. Hence, we may have a specific and particular space to fill in - a fact that our academic freedom may be discouraged and/or encouraged in some ways we do not prefer. Due to the disclaimer journals have, every author is legally, socially, etc. responsible for what they write, self-censorship will control. Having my paper accepted for this conference, the proceedings editors require more text and I have to comply [13]. As researchers, we have to realize that

Journal editors and referees are less likely to recommend publication of articles that challenge their opinions. Publishing houses have been pressured by academics not to produce certain books (3) [10].

Concerning conferences, and in order to get permission and support from my university I have to fill in three forms, and provide all necessary documents to the academic council (they call it "scientific council"). I did not receive any response, regardless of the kind of that response, though I followed instructions to attend this conference.

All these discouraging factors and more are handled in an article entitled "My experience as a Teacher of English as a Foreign Language." One of the barriers discussed in the article is the teaching method adopted by the educational system. Method somewhat hinders academic freedom when

Students do nothing except listen to the teacher and at the end of the semester learn by heart few things to pass the exam. They usually do not bother themselves about the actual text (110) [13].

All the behavioral tendencies may lead to frustration; instead of arguing, analyzing, and discussing a literary text, one may comply with the environment s/he is teaching at. In the same article, another factor that is important in order to practice academic freedom is lack of support from both colleagues and the society in question;

If the colleagues are suspicious of all you do, if they consider you and your subject as a challenge to what they are teaching or doing in their classes. . . then it is a real challenge that requires great efforts (112) [13].

In my college these elements are actual; the society including the colleagues think that teaching literature and analyzing some literary theories may lead to blasphemy. Accordingly, what is taught in literature courses is to some extent limited to telling the story, translating some excerpts, and addressing some language skills like grammar and reading the texts in class. Indeed, this is a way of killing ideas and discouraging academic freedom. Finally, those individuals who are in charge should know that:

Educational institutions have the power to foster academic freedom in many ways...for example, reducing teaching loads, granting travel funds and sabbatical leaves so that faculty members can develop new ideas and exchange ideas with colleagues at other institutions. Many institutions extend the academic freedom of their students by allowing a wide choice of courses (3) [10].

\section{CONCLUSION}

Generally, we have to admit that each institution has its message to society. Having a message, as a basis, is a burden, and the message is an obligation in one way or another. This depends on how one interprets that message. There is no doubt that academics are given more privileges than anyone else. Yet it is clear that professors in institutions are shaping students according to the instructions they are given even when students are given a chance to find out what is going on. As professors and teachers, we are not to impose our opinions on our students. Instead, we have to give them a chance while discussing topics and themes to discover, explore, and expand knowledge for themselves.

On the other hand, academics everywhere should be articulate about shaping students and about admitting their real objectives behind selecting and teaching specific texts whenever they have a chance to choose their texts. They have to be clear regarding their beliefs and tendencies. At the same time, these academics should be open if they want to explore 
and expand knowledge rather than to transmit old knowledge which requires less efforts and freedom.

\section{REFERENCES}

[1] W. O. Douglas. (Oct. 17, 2011). Academic freedom quotes. [Online]. Available: http://thinkexist.com/quotes/with/keyword/academic_freedom/

[2] C. Nelson. (Dec. 21, 2010). Defining academic freedom. [Online]. Available:

https://www.insidehighered.com/views/2010/12/21/defining-academi c-freedom

[3] 1940 Statement of Principles on Academic Freedom and Tenure. [Online]. Available: http://www.aaup.org/file/1940\%20Statement.pdf

[4] E. L. Pincoffs, Introduction of the Concept of Academic Freedom, Austin: U of Texas Press, 1972, pp. vii-xxiv.

[5] W. Shakespeare, Macbeth, London: Penguin Books Ltd, 1994.

[6] J. C. Coldewey and W. R. Streitberger, Everyman in Drama: Classical to Contemporary, NJ: Prentice-Hall Inc., 1998.

[7] S. Hook, "Conflict and change in the academic community," in Defense of Academic Freedom, S. Hook, Ed. New York: The Bobbs-Merrill Company, Inc., 1971, pp. 106-119.

[8] D. R. Shumway, Creating American Civilization: A Genealogy of Academic Literature as an Academic Discipline, Minneapolis: U of Minnesota Press, 1994.
[9] T. L. Pangle, The Ennobling of Democracy: The Challenge of Postmodern Age, Baltimore: The Johns Hopkins UP, 1992.

[10] G. Robinson and J. Moulton, "Academic freedom," Encyclopedia of Ethics, 2nd ed. Garland Publishing, 2001.

[11] J. Wallen, Closed Encounters: Literary Politics and Public Culture, Minneapolis: U of Minnesota Press, 1998.

[12] L. Althusser, "Ideology and ideological sate apparatuses," Lenin and Philosophy and Other Essay, 1971.

[13] G. H. Dohal, "My experience as a teacher of English as a foreign language," Pratidhwani the Echo, 2015

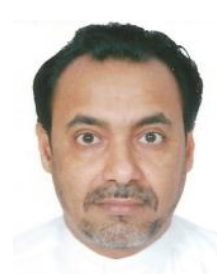

Gassim H. Dohal is an associate professor of English at Al-Imam University in Riyadh, Saudi Arabia. He received his primary education in Gizan, Saudi Arabia. Gassim finished his B.A. degree in English at Al-Imam University. $\mathrm{He}$ is a graduate of both Ball State University, and Indiana University of Pennsylvania, USA. His teaching and research interests include English literature, pedagogy, and literary theory. His work appears in journals such as International Journal of English and Literature, International Journal of Language and Literature, Ain Shams Univ. Annals, and Pratidhwani the Echo. 